\title{
The properties of realized volatility and realized correlation: evidence from the Indian stock market
}

\author{
Konstantinos Gkillas (Gillas)*, Dimitrios I. Vortelinos ${ }^{\dagger}$ and Shrabani Saha ${ }^{\ddagger}$
}

October 15, 2017

\begin{abstract}
This paper investigates the properties of realized volatility and correlation series in the Indian stock market by employing daily data converting to monthly frequency of five different stock indices from January 2, 2006 to November 30, 2014. Using non-parametric estimation technique the properties examined include normality, long-memory, asymmetries, jumps, and heterogeneity. The realized volatility is a useful technique which provides a relatively accurate measure of volatility based on the actual variance which is beneficial for asset management in particular for non-speculative funds. The results show that realized volatility and correlation series are not normally distributed, with some evidence of persistence. Asymmetries are also evident in both volatilities and correlations. Both jumps and heterogeneity properties are significant; whereas, the former is more significant than the latter. The findings show that properties of volatilities and correlations in Indian stock market have similarities as that show in the stock markets in developed countries such as the stock market in the United States which is more prevalent for speculative business traders.
\end{abstract}

Keywords: realized volatility; realized correlation; statistical properties; Indian stock market.

JEL Classification codes: F30; G14; G15; C14; C22; O53.

${ }^{*}$ Corresponding author. Department of Business Administration, University of Patras, Greece. Contact at gillask@upatras.gr and gillask@gmail.com, 0030-6946-506926(tel.).

${ }^{\dagger}$ Lincoln Business School, University of Lincoln, UK. Contact at dvortelinos@lincoln.ac.uk, 0044-1522-835634 (tel.).

${ }^{\ddagger}$ Lincoln Business School, University of Lincoln, UK. Contact at ssaha@lincoln.ac.uk, 0044-1522-835547 (tel.). 


\section{Introduction}

Volatility is central to many issues in finance, ranging from asset management to risk management; in both in developed and emerging markets. However, volatility is latent. Volatility can also be estimated by non-parametric estimators apart from parametric and semi-parametric ones. Any non-parametric estimator estimates quadratic variation, which is regarded as the best estimator of integrated (latent) volatility.The stylized facts (properties) of volatility are active research issues; especially for the emerging stock markets. However, not much research has been done so far which examines the properties of volatility in particular for the emerging markets. Furthermore, the existing empirical literature has investigated this issue mainly by using parametric models,

In this paper, we emphasize the importance of realized volatility and correlation estimation via the realized range estimator for the Indian stock market; an emerging and quite promising market. We focus on a period which incorporates various stock market booms and crashes, from January 2, 2006 to November 30, 2014. The dataset includes four indices of the National Stock Exchange of India (NSEI), such as CNX-500, CNX-100, CNX NIFTY JUNIOR (CNX-J) and CNX NIFTY (CNX). In addition, one index from the Bombay stock exchange (BSE) i.e., S\&P BSE SENSEX (BSESN) is been used. (BSE):

\section{S\&P BSE SENSEX (BSESN).}

The empirical literature has not investigated the properties of realized volatility series of the Indian stock market. In addition, previous studies, which have examined emerging markets (including India), are scattered. In case volatilities are estimated non-parametrically, literature suggests various models to capture the respective properties for prediction and forecasting purposes. However, the parametric estimators of volatility can incorporate volatility properties in the parametric estimators only. Nevertheless, the parametric volatility estimator cannot incorporate all volatility properties in a single model. The recent literature suggests using mixed parametric models to estimate volatility more accurately. ${ }^{1}$ We employ the most well-known non-parametric volatility estimators which incorporate the most parsimonious volatility properties. Furthermore, to the best of our knowledge, realized correlation for the Indian stock market has not been extensively examined in literature. The realized volatility is a useful technique which provides a relatively accurate measure of volatility based on the actual variance which is beneficial for asset management in particular for non-speculative funds. In this paper, we investigate the following properties of realized volatility and realized correlation series of the Indian stock market: normality, long memory, asymmetry, discontinuity and heterogeneity. Also, this paper fills the gap by estimating volatility and correlation via a contemporary realized (range) volatility and correlation estimator non-parametrically.

Our findings indicate that the properties of volatilities and correlations of the Indian stock market

\footnotetext{
${ }^{1}$ In this paper, we do not focus on such models, because the purpose of the paper is not to find the best parameterisation of a model for volatility estimation.
} 
show similar properties of volatilities and correlations like developed stock markets, such as the United States (US) stock market. These results pave the way towards the investigation of asset and risk management in the Indian stock market or any other emerging financial market.

The rest of the paper is organised as follows: section 2 reviews the literature regarding the impact of the 2008 financial crisis in India, the Indian stock market in general, volatility and correlation in the Indian stock market, and the properties of volatility and correlation. Section 3 describes the data. Section 4 presents the realized range estimators of volatility and correlation, the long-memory estimator and FIGARCH model, asymmetric tests, asymmetry equations and asymmetic GARCH-type models, the jumps detection schemes, and the HAR-J and HAR-CJ models. Section 5 deploys the results of normality, long memory, asymmetry, discontinuity, and heterogeneity properties of volatility and correlation series. Section 6 provides concluding remarks.

\section{Literature review}

\subsection{8 financial crisis and India}

Economic disasters have been regarded as universal occurrence all over the contemporary history of the human race. All together, around 200 financial and economic disasters had happened since late 1970 until 2013. Das, Kumar, Debnath and Mandal (2012) examined economic disasters in detail. Moreover, the general aspect of approximately every disaster has been considered as a speed up method. This means exploring the fastest and most superior profits as well as a huge divergence among desire for threat and the ability for tolerating it. As illustrated in Mandelbrot and Hudson (2009), the worldwide economic consideration in 2008 has been considered as an astounding illustration of covetousness and hedonism of the organizations in the USA. There is a big difference between these crises and the recent 2008 one. The latter emerged from the extremely center of the globalised financial system and has not been restricted to a particular area. Furthermore, the warmth of chaos was experienced in the entire global financial system; however of unreliable length, same way as a pebble in a pool, its waves moved in even outward direction. It has been recognised that those who break the rules do create repercussions for the people around them. Several corporations of the Wall Street penniless the fiscal official procedure and the public generally and the US especially tire the load of it. The sub-prime disaster, which has been regarded as nastiest after vast dejection of 1930s obtained its platform around 2007 and influenced the complete fiscal and economic system in the US and United Kingdom (UK). On the other hand, the breakdown of Lehman Brothers in the middle of September 2008 additionally provoked the circumstances directing to a crisis of buoyancy in the fiscal markets. The harshness and abruptness of the crisis could be observed from the prediction of International Monetary Fund (IMF) for the worldwide financial system. Hence, the IMF depicted a worldwide collapse with depressing effect on the gross domestic product (GDP) of 
the world in the year 2009-2010, which occurred for the first time in sixty years.

The prime cause of collapse was US housing fizz that emerged high in 2006. Thus, according to Prasad and Reddy (2009), throughout this era, mortgage agents fascinated by the huge payments, attracted purchases with meagre credit to admit housing mortgages with small or no deposits and not including credit checks. Financial institutions provided funds on the supposition that housing values would increase persistently. Nevertheless, the house prices in America have increased by $130 \%$ between 1998 and 2007 . This reality fizz increased the demand for houses as economic resources. Banks and other loan agencies afterward repackaged these debts with other high-risk debts and sold them to global financiers by forming new fiscal tools called collateralised debt obligations (CDOs). Thus, threat was deceased multifold in the global economic markets. Hence, because of excess inventory of houses and enhanced interest rates, there was a slump in housing values between 2007 and 2008 that turned out into an augmented evasions and foreclosure actions that distorted the housing movement. The result of this collapse was experienced internationally for the reason that CDOs were sold globally and circumstances turned out to be more devalued because several banks of Wall Street had rented 50 times more than the actual value (Mandelbrot and Hudson, 2009). Various financial institutions that had purchased securities of billion dollars' worth derived from mortgages were in problem currently. This chaos happened to emerge in the middle of 2007 intensified largely since August 2008 (Monhan, 2009). Moreover, this impact might have been noticed in the international financial markets since then.

Originally, the financial system of India appeared to be comparatively confirmed from this collapse. Rather the outcome was optimistic as India obtained increased organizational investment flows from overseas during the year 2008 when the line of the subprime mortgages had begun developing in the United States. The amount of total inflows in India during 2008 was approximately $\$ 21$ billion. However, India could not protect itself from the unfavourable incidents in the global markets soon after; although its banks had insignificant asset in the fiscal tools like CDOs. Moreover, the instant pessimistic influence of collapse on the country was experienced only after the meltdown of Lehman Brothers with the loss of organizational overseas investment from the equity market and rising interest rates in capital market that got boosted about $30 \%$ throughout the month.

Various factors of the Indian financial system, like: Indian exchange rates, IT, foreign investment, foreign exchange outflows, unemployment rate, volume of exports, stock market and banking, have been influenced by the 2008 crisis started from the United States (Prasad and Reddy, 2009). However, the most instantaneous outcome was experienced on the meltdown of its foreign exchange and equity markets.

During the period between January and October 2008, the RBI reference rate for the rupee cut down by almost $30 \%$. Another market that was with most horribly struck by this disaster was the Indian stock market. The Sensex index accounted over 21,000 points in January, 2008 and felled lower than 10,000 points in October, 2008. A declining stock market index shows the reduction of the asset atmosphere 
whereas an increasing stock index shows more poise and reliability of the financial system. As a result, it is not uncertain to believe that worldwide economic collapse had reduced the self-confidence of investors in the Indian stock markets.

In the current situation, stock return volatility is a subject of big concern for investors and policy makers. High variations in stock return or stock return volatility are detrimental for the development of a financial system. Practical facts show that economic solidity is believed to be under risk more by unexpected alterations in instability rather than by a constant enhancement in the attitude of instability. Various researchers have observed the time fluctuation in the instability with the affect of several market shocks and liberalization transformations. Rao and Kaur (2009) examined the influence of financial collapse of the world on the NCDEX commodity exchange.

\subsection{Indian stock market}

Bhar and Nikolova (2009), examined the level of integration and the dynamic relationship between BRIC (Brazil, Russia, India and China) countries, their respective regions and the world and found that India had the highest level of regional and global integration among the BRIC countries. Durand, Lan and $\mathrm{Ng}$ (2011) examined conditional betas using both local and world excess returns and a model using both local and world excess returns in India's and other emerging stock markets. Majumder (2012) proposed a transformation on original market returns in the objective of relaxing the strong assumption of market efficiency behind application of an asset pricing model in the Indian market. Giannikos and Gousgounis (2012) provided evidence that opinion dispersion leads to higher overpricing in the Indian equity market in which short sales are prohibited. French and Naka (2013) found that positive shocks to US equity flows to India elicited an insignificant response to returns; and, shocks to dividend yields have a strong negative influence on US equity flows. Anand (2014) measured the relationship between risk and return, and the effect of diversification on market risk in Indian stock market by applying a market index model.

\subsection{Volatility of the Indian stock market}

Pandey (2002) reported range estimates of volatility performed better than realized volatility in forecasting the volatility of the S\&P CNX Nifty Indian stock market index.

In the present paper, volatility is estimated as in Martens, and van Dijk (2007) with the realized range estimator. Bhaduri and Samuel (2009) analyzed the correlation between the Indian stock market and other world markets. Tripathy and Gil-Alana (2010) estimated volatility in the India NSE via (i) historical/rolling window moving average estimator, (ii) exponentially weighted moving average (EWMA), (iii) generalized autoRegressive conditional heteroskedasticity (GARCH) model, (iv) extreme value indicators (EVI) and (v) volatility index (VIX). Dixit, Yadav and Jain (2010) examined the "in-the-sample" and "out-of-the-sample" forecast efficiency of implied volatilities of S\&P CNX Nifty index options, via a 
GARCH and an EGARCH (exponential GARCH) model.

Chiang, Chen and Lin (2013), investigated the spillover effects of returns and volatility in the US stock market on the stock markets of Brazil, Russia, India, China and Vietnam (BRICVs) via an ARJI (autoregressive conditional jump intensity) model, found that India demonstrated the lowest total longrun risk. Bentes and Menezes (2013) found that the feasible generalized least squares (FGLS) model better forecasts realized volatility than ordinary least squares (OLS) and asymmetric ordinary least squares (AOLS) in the stock markets of India, US, Hong Kong, China and South Korea. Kumar and Jaiswal (2013) found that Black Scholes implied volatility dominates the forecasting efficiency over the VIX even though both estimates are biased. A recent study on the properties of realized range by Todorova and Soucek (2014), uses the realized (Parkinson) range estimator for accuracy without noise daily volatility estimates. Kumar (2014) researched spillover effects between Indian exchange rates relative to US Dollar, Great Britain pound, Euro and Japanese Yen via a parametric vector autoregressive model for the mean and a multivariate GARCH for volatility (VAR(1)-MVGARCH) model. Garg and Vipul (2015) provided evidence from the Indian options market that the forecasts based on realized volatility are significantly more efficient and less biased than those based on model-free implied volatility. They also found that the volatility risk premium can provide economic benefits only to those option writers, who have sufficiently low transaction costs. Also, Tripathy and Gil-Alana (2015) researched the in- and out-of-sample properties of volatilities via different GARCH models. Bentes (2017) investigates the relation between implied and realized volatility using monthly data from the BRIC countries, and shows that implied volatility is an unbiased estimate of realized volatility for India and that implied volatility was not found to be efficient in any of the BRIC countries.

\subsection{Correlation and the Indian markets}

Martens and van Djik (2007) estimated the correlation series via the realized (Parkinson) range correlation estimator. Jumps are detected in correlation series via the jump test statistic of Andersen, Bollerslev and Diebold (2007). Bianconi, Yoshino and de Sousa (2013) examined the evolution of unconditional and conditional correlations between stocks and bonds of BRIC nations before and after the September 2008 financial crisis.

\subsection{Volatility and correlation properties}

The property of heteroscedasticity and asymmetry in volatility series of the Indian stock market (S\&P CNX Nifty index) was examined by Karmakar (2007). He found that volatility which exhibits clustering, high persistence and predictability, is an asymmetric function of past innovation. Amira Taamouti and Tsafack (2011) analyzed the Granger-causality asymmetries on correlations in terms of returns- and volatilities- news. Alper, Fendoglu and Saltoglu (2012) showed evidence that the Mixed Data Sampling 
(MIDAS) model provided more accurate weekly volatility forecasts than a $\operatorname{GARCH}(1,1)$ model for the Indian and other nine emerging stock markets. A recent study on discontinuity's (jumps') importance in volatility prediction is Atak and Kapetanios (2013). The benefit of modelling jumps in realized volatility is deployed in Liao (2013). A recent study utilizing the benefits of HAR is Sevi (2013). Atak and Kapetanios (2013) compared the out-of-sample performance of HAR to factor models. A recent study on the properties of jumps and asymmetries in realized volatility is Soucek and Todorova (2014). ${ }^{2}$

\section{Data}

We employ daily data for the main stock indices in India, focusing on a period which incorporates various stock market booms and crashes including the 2008 global financial crisis. The dataset contains four indices of the National Stock Exchange of India (NSEI): CNX-500, CNX-100, CNX NIFTY JUNIOR (CNX-J) and CNX NIFTY (CNX); and one index of the Bombay stock exchange (BSE): S\&P BSE SENSEX (BSESN). All data series begin on January 2, 2006 and end on November 30, 2014. For all indices, trading takes place from 9:00 to 15:30 Indian standard time ${ }^{3}$. Trading times are common across all Indian stock exchanges. The prices of indices are expressed in local currency (Indian rupee). In this study, we convert the daily data into monthly frequency to examine the volatility and correlation series in the Indian stock market.

The Indian stock market is one of the oldest in Asia, operating since 1875. The creation and empowerment of Securities and Exchange Board of India (SEBI) has helped in providing higher level accountability in the market. New institutions like National Stock Exchange of India (NSEIL), National Securities Clearing Corporation (NSCCL), and National Securities Depository (NSDL) have been the new agents helping to clean the system and providing safety to the public at large to invest. With modern technology in hand, these institutions have set benchmarks and standards for others to follow. The microstructure changes brought about reduction in transaction cost that helped investors to lock in a faster and cheaper deal. The major changes in the capital market have resulted in the complete transformation of structure and composition of the market. In addition, Indian capital markets also have started trading on derivative products in line with the developed countries.

\section{Methodology}

This paper fill the gap by estimating non-parametrically volatility and correlation via a contemporary realized (range) volatility and correlation estimator

\footnotetext{
${ }^{2}$ We examine the Granger-causality asymmetries on correlations in the main five Indian indices. The scope of asymmetric regressions is to detect, apart from asymmetries, the existence of incremental information from indicators.Furthermore, the significance of heterogeneity- and jumps- properties of volatilities (correlations) is examined via the HAR-J and HAR-CJ models.

${ }^{3}$ Indian standard time is 5 hours and 30 minutes later than the Greenwich Mean Time (GMT) in the UK.
} 


\subsection{Realized (range) volatility estimation}

Volatility is latent. However, volatility can be estimated by apart from parametric and semi-parametric estimators, also by non-parametric However, apart from the parametric and semi-parametric estimators volatility can be estimated by non-parametric estimators as well. Any non-parametric estimator estimates quadratic variation, which is considered as the best estimator of integrated (latent) volatility. In the present paper, volatility is estimated by the realized range estimator. This estimator is a combined estimator between realized volatility and range estimators. Andersen, Bollerslev, Diebold and Labys (2001) theoretically developed and empirically examined the realized volatility estimator. Parkinson (1980) introduced the range estimator in the literature. Martens, and van Dijk (2007), under both simulation experiments and empirical study, were the first to provide evidence of more accurate estimates coming from realized Parkinson range-based estimator than an unrestricted realized volatility estimator. Christensen, Oomen and Podolskij (2010) and Christensen and Podolskij (2012) settled the use of the realized range estimator in a daily frequency. More recently, Todorova (2012) empirically examined the properties as well as the accuracy of the realized (Parkinson) range estimator.

We employ the realized (Parkinson) range estimator to nonparametrically estimate volatility in a monthly frequency. According to literature, this estimator is defined as:

$$
R V_{t}^{R R}=\frac{1}{4 \log (2)} \sum_{i=1}^{m}\left(h_{i, t}-l_{i, t}\right)^{2}
$$

where $h_{i, m}$ and $l_{i, m}$ are the within the $i$-th day high and low logarithmic prices for each $t$ month; $m$ is the number of trading days in a month $(\approx 21$; in average).

\subsection{Realized (range) correlation estimation}

Covariance as well as correlation is estimated non-parametrically. The best non-parametric estimator in a multivariate level is realized correlation. Barndorff-Nielsen, and Shephard (2006a) introduced the realized covariance and realized correlation estimator. The realized covariance is given by the crossproducts of the two daily asset returns series throughout each month:

$$
\operatorname{Rov}_{t}^{R V}=\sum_{i=1}^{m} r_{a, i, m, t} \cdot r_{b, i, m, t}
$$

where $r_{a, i, m, t}$ and $r_{b, i, m, t}$ are the daily returns series for the $a$ and $b$ corresponding assets; and $m$ is the number of trading days in a month $(\approx 21$; in average). Realized covariance was also discussed in Andersen, Bollerslev, Diebold and Labys (2001). In the absence of noise, $R C o v_{t}^{R V}$ is a consistent estimator of covariance as the sampling frequency increases. The realized range correlation coefficient $\left(R C_{t}^{R R}\right)$ comes from the $R \operatorname{Cov}_{t}^{R V}$ devided by the square roots of the realized range volatility $R V_{t}^{R R}$ 
estimates of two assets $\left(R V_{t, a}^{R R}\right.$ and $\left.R V_{t, b}^{R R}\right)$.

$$
R C_{t}^{R R}=\frac{R \operatorname{Cov}_{t}^{R V}}{\sqrt{R V_{t, a}^{R R}} \sqrt{R V_{t, b}^{R R}}}=\frac{\sum_{i=1}^{m} r_{a, i, m, t} \cdot r_{b, i, m, t}}{\sqrt{\frac{1}{4 \log (2)} \sum_{i=1}^{m}\left(h_{a, i, m, t}-l_{a, i, m, t}\right)^{2}} \sqrt{\frac{1}{4 \log (2)} \sum_{i=1}^{m}\left(h_{b, i, m, t}-l_{b, i, m, t}\right)^{2}}}
$$

where realized range volatility $R V_{t}^{R R}$ estimates are estimated as in sub-section 4.1 for each $t$ month and $i$ trading day. Martens and van Djik (2007) introduced the realized Parkinson range-based volatility estimator (in a univariate level) and Brandt and Diebold (2006) introduced the realized (Parkinson) range-based covariance and correlation estimators.

\subsection{Long memory}

\subsubsection{Long memory estimator}

The long-memory parameter $\mathrm{d}$ is estimated in a semiparametric fashion. The Andrews and Guggenberger (2000) (AG, henceforth) estimator is considered. $d$ is least squares estimated in the frequency-domain regression

$$
\ln I\left(\lambda_{i}\right)=\gamma_{0}-d \cdot \ln \left(4 \cdot \sin ^{2}\left(\frac{\lambda_{i}}{2}\right)\right)+\sum_{j=1}^{J} \gamma_{j} \lambda_{i}^{2 j}+\epsilon\left(\lambda_{i}\right)
$$

where $I($.$) is the periodogram of data in harmonic frequencies \lambda_{i}=\frac{2 \pi i}{n}$ with $i=1, \ldots, m<n$. The bandwidth parameter $m$ is allowed to vary between $[\sqrt{n}]$ and $\left[n^{0.8}\right]+1$, where $[x]$ is the integer part of $x$; $J=1$, and $c_{J}=2.25$. The limiting distribution in the above equation was obtained by AG (2000) under the assumption of stationarity $(\mathrm{d}<0.5)$. This assumption is true for realized volatility and realized correlations in developed countries. According to Bandi and Perron (2006), the AG estimator reduces the asymptotic mean squared errors of the d estimates relative to the GPH estimator. The degree of fractional integration can also be estimated by running OLS regressions of log-autocorrelations on loglags as introduced in Beran and Ocker (2001) and empirically recently researched in Chiriac, and Voev (2011).

\subsubsection{FIGARCH model}

The models used in this research consist of an autoregressive model for the conditional mean and a first-order GARCH-type model for the conditional variance, as follows:

$$
r_{t}=c+u_{t}
$$




$$
u_{t}=h_{t} z_{t}, z_{t} \sim \text { i.i.d. }(0,1)
$$

where $r_{t}$ is the Indian stock index price return on month $\mathrm{t}, u_{t}$ is the error term, $z_{t}$ is a white noise process, and $h_{t}$ is the conditional standard deviation. We present results for the FIGARCH (fractionally integrated GARCH) model.

The FIGARCH model, as proposed by Baillie, Bollerslev and Mikkelsen (1996), captures the temporal dependencies (long memory) in predicted volatility. Following Bentes (2014) and (2016), the FIGARCH(1,d,1) model can be modelled as follows:

$$
h_{t}^{2}=\omega+\beta \cdot h_{t-1}^{2}+\left[1-\beta \cdot L-(1-\varphi \cdot L) \cdot(1-L)^{d}\right] \cdot u_{t}^{2}
$$

where:

$$
0<d<1
$$

\subsection{Asymmetries}

\subsubsection{Asymmetric tests}

The assumption of symmetry requires that the skewness should be equal to zero. In this sub-section, we apply two different statistical tests, in order to examine the asymmetry in conditional distribution. The first test is a bootstrap non-parametric test of asymmetry for the null hypothesis that the distribution is symmetric with skewness equal to 0 . We generate the sampling distribution by bootstrapping and re-sampling from the original data and we apply a single-tailed test for the null hypothesis that the distribution is symmetric with skewness equal to 0 . For robustness propose, we also apply the D' Agostino (1970) test, in order to examine if the skewness is equal to zero. ${ }^{4}$

\subsubsection{Asymmetry equations}

Asymmetries are examined as in Amira, Taamouti and Tsafack (2011). Standard errors (SE) in all equations are based on the Newey-West (NW) estimator of the variance-covariance matrix (see, Dufour, Pelletier and Renault, 2006). The asymmetriy property in volatilities (correlations) is analyzed with upturn and downturn volatilities (correlations). Volatility (correlation) is decomposed into upturn and downturn volatility (correlation). Their corresponding impact on correlation (volatility) is examined. So,

\footnotetext{
${ }^{4} \mathrm{D}^{\prime}$ Agostino (1970) test has such null hypothesis and is useful to detect a significant skewness in normally distributed data. It is also a test for the hypothesis of normality.
} 


$$
(1-L)^{d_{R C_{t}^{R R}}^{R}} R C_{t}^{R R}=a+b \cdot D_{+} \cdot R C_{t-1}^{R R}+\gamma \cdot D_{-} \cdot R C_{t-1}^{R R}+u_{i, t}
$$

or

$$
(1-L)^{d_{R V_{t}^{R R}}^{R R}} R V_{t}^{R R}=a+b \cdot D_{+} \cdot R V_{t-1}^{R R}+\gamma \cdot D_{-} \cdot R V_{t-1}^{R R}+u_{i, t}
$$

where $D_{+}=\left\{\begin{array}{cc}1 & r_{i, t} \geq 0 \\ 0 & r_{i, t}<0\end{array} \quad, D_{-}=1-D_{+}\right.$and $d_{R C_{t}^{R R}}\left(d_{R V_{t}^{R R}}\right)$ is the AG long memory estimate of realized correlation $\left(R C_{t}^{R R}\right)$ and volatility $\left(R V_{t}^{R R}\right)$, respectively.

\subsubsection{Asymmetric GARCH-types models}

The models used in this research consist of an autoregressive model for the conditional mean and a first-order GARCH-type model for the conditional variance, as follows:

$$
\begin{gathered}
r_{t}=c+\sum_{i=1}^{S} \varphi_{i} r_{t-i}+u_{t} \\
u_{t}=h_{t} z_{t}, z_{t} \sim \text { i.i.d. }(0,1)
\end{gathered}
$$

where $r_{t}$ is the Indian stock index price return on month $\mathrm{t}, u_{t}$ is the error term, $z_{t}$ is a white noise process, and $h_{t}$ is the conditional standard deviation. Following Ferreira, Menezes and Mendes (2007) and Bentes, Menezes and Ferreira (2013), we present results for different asymmetric GARCH-type models for robustness proposes, namely EGARCH and GJR-GARCH.

The EGARCH model, as proposed by Nelson (1991), captures the effect of external unexpected shocks on the predicted volatility. The $\operatorname{EGARCH}(1,1)$ model can be modelled as follows:

$$
\log \left(h_{t}^{2}\right)=\omega+\alpha\left[\left|\frac{u_{t-1}}{h_{t-1}}\right|-\sqrt{\frac{2}{\pi}}\right]+\beta \cdot \log \left(h_{t-1}^{2}\right)+\delta \cdot \frac{u_{t-1}}{h_{t-1}}
$$

The GJR-GARCH model, as proposed by Glosten, Jagannathan and Runkle (GJR) (1993), captures the effect of positive and negative shocks on the volatility. The GJR-GARCH(1,1) model can be modelled as follows:

$$
h_{t}^{2}=\omega+\alpha \cdot u_{t-1}^{2}+\beta \cdot h_{t-1}^{2}+\gamma \cdot u_{t-1}^{2} I_{t-1}
$$

where: 


$$
I_{t-1}=\left\{\begin{array}{ccc}
1 & \text { if } & u_{t-1}<0 \\
0 & \text { if } & u_{t-1} \geq 0
\end{array}\right.
$$

\subsection{Jumps detection schemes}

\subsubsection{Volatility jumps}

The jumps detection scheme employed was the one introduced in Huang and Tauchen (2005) and finalised in Andersen, Bollerslev and Diebold (2007). This detection scheme of jumps in volatility series depends on the idea that volatility is split into a jumps and a continuous component of volatility. The scheme requires an estimator that excludes jumps. Barndorff-Nielsen and Shephard (2006a and 2006b) set up an accurate estimate of the integrated variance excluding jumps; entitled as bipower variation:

$$
R V_{t}^{B P V}=\mu_{p}^{-2} \sum_{i=2}^{m}\left|r_{i, m}\right|\left|r_{i-1, m}\right|
$$

In general, $R V_{t}^{R R}-R V_{t}^{B P V} \rightarrow \lambda_{t}$ which is the jump component of volatility and $R V_{t}^{R R}$ denotes realized range. Huang and Tauchen (2005) proposed the following test statistic (also settled and extensively examined in Andersen, Bollerslev and Diebold, 2007):

$$
Z_{t}=m^{1 / 2} \frac{\log \left(R V_{t}^{R R} / R V_{t}^{B P V}\right)}{\left[\left(\mu_{1}^{-4}+2 \mu_{1}^{-2}-5\right)\left\{T P Q_{t}\left(R V_{t}^{B P V}\right)^{-2}\right\}\right]^{1 / 2}}
$$

A jump is indicated as $\tilde{J}_{t}^{R V^{R R}}=\max \left(R V_{t}^{R R}-R V_{t}^{B P V}, 0\right)$. The following test-based version for defining a day with a significant jump is used:

$$
J_{t}^{R V^{R R}}=I\left(Z_{t}>\Phi_{\alpha}\right)\left(R V_{t}^{R R}-R V_{t}^{B P V}\right)
$$

The continuous component of volatility is defined as $C_{t}^{R V^{R R}}=R V_{t}^{R R}-J_{t}^{R V^{R R}}$. $\Phi_{\alpha}$ is the critical value of the standard normal distribution at $\alpha$ level of significance. Here, $J_{t}$ is the sample estimator of the theoretical jump component $\lambda_{t}$ in the sense that $J_{t} \rightarrow \lambda_{t}$.

\subsubsection{Correlation jumps}

The jump detection scheme for correlations employed was introduced and empirically examined in Huang and Tauchen (2005) and Andersen, Bollerslev and Diebold (2007) respectively. As far as the distributional properties of correlation series are not by far different to volatility properties, the test statistic of Andersen, Bollerslev and Diebold (2007) is employed for detecting jumps in realized correlations: 


$$
J_{t}^{R C^{R R}}=I\left(\max \left(\left|R C_{t}^{(R R)}-R C_{t}^{(B V)}\right|, 0\right)>c\right) \cdot\left(R C_{t}^{(R R)}-R C_{t}^{(B V)}\right)
$$

where $R C_{t}^{(R R)}$ is the realized range correlation estimator and $R C_{t}^{(B V)}$ is realized bipower-variation correlation estimator. ${ }^{5}$ The threshold $c$ can take different values. The value used throughout the paper is $c=0.05$, which is a benchmark value to use. The continuous component of correlation is defined as:

$$
C_{t}^{R C^{R R}}=R C_{t}^{(R R)}-\max \left(\left|R C_{t}^{(R R)}-R C_{t}^{(B V)}\right|, 0\right)
$$

where naturally $J_{t}^{R C^{R R}}=\max \left(\left|R C_{t}^{(R R)}-R C_{t}^{(B V)}\right|, 0\right)$. This jump detection test is very strict. So, it captures only high in magnitude jumps; and, only one jump per day.

\subsection{HAR-J and HAR-CJ models}

Both heterogeneous autoregressive model with jumps (HAR-J) and heterogeneous autoregressive model with continuous and jumps components (HAR-CJ) have been often researched in literature. Ghysels, Santa-Clara, and Valkanov (2006), Andersen, Bollerslev and Diebold (2007), Clements Galvao and Kim (2008) and Corsi (2009) set up the scheme for a further empirical analysis of jumps and heterogeneity properties. Both models examine both the heterogeneity and jumps properties of volatility and correlation series. The present paper employs both models in their original outline in a monthly frequency. So, instead of daily, weekly and monthly volatilities and components, one month (1M), five months (5M) and twenty months $(20 \mathrm{M})$ lagged volatilities and components are employed to examine heterogeneity and jumps.

\subsubsection{Volatility}

The HAR-J model models both heterogeneity and jumps in realized range volatility $R V_{t}^{R R}$ series:

$$
R V_{t}^{R R}=\beta_{0}+\beta_{1 M} R V_{t-1, t}^{R R}+\beta_{5 M} R V_{t-5, t}^{R R}+\beta_{20 M} R V_{t-20, t}^{R R}+\gamma_{J} J_{t-1, t}^{R V^{R R}}
$$

$\beta_{1 M}, \beta_{5 M}, \beta_{20 M}$ and $\gamma_{J}$ are the regression coefficient estimates for the one month (1M), five months $(5 \mathrm{M})$ and twenty months $(20 \mathrm{M})$ lagged volatilities and jumps series of the realized range volatility $R V_{t}^{R R}$ series.

The model in which heterogeneity is distinguished between the continuous and jumps components of realized range volatility $R V_{t}^{R R}$ series is the HAR-CJ model:

\footnotetext{
${ }^{5}$ The realized bipower variation correlation is $R C_{t}^{(B V)}=\frac{R \operatorname{Cov}_{t}}{\sqrt{R V_{t, a}^{(B V)}} \sqrt{R V_{t, b}^{(B V)}}}=\frac{\sum_{i=1}^{m} r_{a, i, m} r_{b, i, m}}{\sqrt{\mu_{p}^{-2} \sum_{i=2}^{m}\left|r_{a, i, m}\right|\left|r_{a, i-1, m}\right|} \sqrt{\mu_{p}^{-2} \sum_{i=2}^{m}\left|r_{b, i, m}\right|\left|r_{b, i-1, m}\right|}}$ where $\mu_{p}=\mathrm{E}\left(|Z|^{p}\right)$ is the mean of the $p$-th absolute moment of a standard normal distribution. For a detailed analysis of the properties of the realized bipower- estimator, see Barndorff-Nielsen, and Shephard (2006b).
} 


$$
R V_{t}^{R R}=\left\{\begin{array}{c}
\beta_{0}+\beta_{C_{1 M}} \cdot C_{t-1, t}^{R V^{R R}}+\beta_{C_{5 M}} \cdot C_{t-5, t}^{R V^{R R}}+\beta_{C_{20 M}} \cdot C_{t-20, t}^{R V^{R R}}+ \\
\gamma_{J_{1 M}} \cdot J_{t-1, t}^{R V^{R R}}+\gamma_{J_{5 M}} \cdot J_{t-5, t}^{R V^{R R}}+\gamma_{J_{20 M}} \cdot J_{t-20, t}^{R V^{R R}}+\epsilon_{t}
\end{array}\right.
$$

$\beta_{C_{1 M}}, \beta_{C_{5 M}}, \beta_{C_{20 M}}, \gamma_{J_{1 M}}, \gamma_{J_{5 M}}$ and $\gamma_{J_{20 M}}$ are the regression coefficient estimates for the one month (1M) continuous, five months (5M) continuous, twenty months (20M) continuous, one month (1M) jumps, five months (5M) jumps and twenty months (20M) jumps series of the realized range volatility $R V_{t}^{R R}$ series.

\subsubsection{Correlation}

The HAR-J model models both properties heterogeneity and jumps in realized range correlations $R C_{t}^{R R}$ series:

$$
R C_{t}^{R R}=\beta_{0}+\beta_{1 M} R C_{t-1, t}^{R R}+\beta_{5 M} R C_{t-5, t}^{R R}+\beta_{20 M} R C_{t-20, t}^{R R}+\gamma_{J} J_{t-1, t}^{R C^{R R}}
$$

$\beta_{1 M}, \beta_{5 M}, \beta_{20 M}$ and $\gamma_{J}$ are the regression coefficient estimates for the one month (1M), five months $(5 \mathrm{M})$ and twenty months $(20 \mathrm{M})$ lagged volatilities, and jumps series of the realized range correlation $R C_{t}^{R R}$ series.

The model in which heterogeneity is distinguished between the continuous and jumps components of realized range correlation $R C_{t}^{R R}$ series is the HAR-CJ model:

$$
R C_{t}^{R R}=\left\{\begin{array}{c}
\beta_{0}+\beta_{C_{1 M}} \cdot C_{t-1, t}^{R C^{R R}}+\beta_{C_{5 M}} \cdot C_{t-5, t}^{R C^{R R}}+\beta_{C_{20 M}} \cdot C_{t-20, t}^{R C^{R R}}+ \\
\gamma_{J_{1 M}} \cdot J_{t-1, t}^{R C^{R R}}+\gamma_{J_{5 M}} \cdot J_{t-5, t}^{R C^{R R}}+\gamma_{J_{20 M}} \cdot J_{t-20, t}^{R C^{R R}}+\epsilon_{t}
\end{array}\right.
$$

$\beta_{C_{1 M}}, \beta_{C_{5 M}}, \beta_{C_{20 M}}, \gamma_{J_{1 M}}, \gamma_{J_{5 M}}$ and $\gamma_{J_{20 M}}$ are the regression coefficient estimates for the one month (1M) continuous, five months (5M) continuous, twenty months (20M) continuous, one month (1M) jumps, five months $(5 \mathrm{M})$ jumps and twenty months $(20 \mathrm{M})$ jumps series of the realized range correlation $R C_{t}^{R R}$ series.

\section{Empirical findings}

In this section, we provide an extensive analysis of the volatility and correlation properties of the main Indian stock indices. For both volatility and correlation series, the properties examined are: (i) normality, (ii) long-memory, (iii) asymmetries, (iv) jumps and (v) heterogeneity. The properties are investigated via: (i) the magnitude of the average-, skewness- and kurtosis- values as well as the CVM normality test and JB normality test; (ii) the Andrews and Guggenberger (2000) estimator and FIGARCH model as in Bentes, Menezes and Mendes (2008); (iii) asymmetric tests (bootstrap non-parametric test of asymmetry and D' Agostino (1970) test), asymmetric regressions (following Amira Taamouti and Tsafack, 2011) and asymmetric GARCH-type models (following Bentes, Menezes and Ferreira, 2013); (iv) frequency of 
occurrence of jumps and jumps coefficients in the HAR-J and HAR-CJ models; and (v) heterogeneous volatility and continuous volatility series in the HAR-J and HAR-CJ models.

\section{$5.1 \quad$ Normality}

Table 1A reports descriptive statistics for volatility series. Average values of returns and volatilities are compatible between all Indian stock indices. Skewness values are around 8 and kurtosis values at around 70. All statistic values are extreme; indicating lack of normality. So, returns are far from being normal; as expected. Fat tails are also evident. The kurtosis of returns is much higher than that of a normal distribution at intraday frequency and tends to decrease as the return length increases. Thus, the probability density functions (pdf) of returns are leptokurtic with shapes depending on the time scale and presenting a very slow convergence of the Central Limit Theorem to the normal distribution. These results are consistent with Jarque-Bera (JB) test; in which, normality is rejected in all series of returns. However, normality is not rejected by the Cramer-von Mises (CVM) test on returns. Moreover, the skewness and kurtosis values for volatilities are close to 3 and between 11 and 13, respectively; indicating distributions not strongly adverse to normality. However, normality is rejected by the CVM test and JB test on volatilities of all Indian stock indices.

Table 1B reports descriptive statistics for correlations series. As expected, all correlations are positive, and all higher than 0.50. Positive correlations indicate that there are no diversification effects/benefits between different stock indices / exchanges in India. Their skewness values are close to 0 and their kurtosis values between 3 and 10; both statistics indicate a distribution close to normality. The normality in correlations contradict to the results in Andersen, Bollerslev, Diebold and Ebens (2001), where they found realized (co)variances are extremely right skewed and leptokurtic. However, normality is rejected by the CVM and JB normality tests.

\subsection{Long memory}

Table $2 \mathrm{~A}$ reports the long-memory estimates of volatilities and correlations series. All degrees of long memory estimates are statistically significant. Long memory is evident in both volatility and correlation series. The persistency in volatilities was also evident to Andersen and Bollerslev (1997), Andersen, Bollerslev, Diebold and Labys (2001) and Granger (2003), among many other more contemporary empirical studies. Literature indicates that realized (co)variances and correlations inherit long memory (see, Andersen, and Bollerslev, 1997, and Andersen, Bollerslev, Diebold, and Ebens, 2001, among others). The magnitude of persistency of both volatilities and correlations in the present paper is lower than those of developed markets as examined in these studies. The lack of strong in-magnitude persistency may be explained by the monthly frequency of volatility and correlation estimates, compared to the daily frequency in these studies. According to the market efficiency theory, it is expected that long memory 
will be lower in emerging than developed financial markets.

Table 2B reports the estimates of the FIGARCH $(1, \mathrm{~d}, 1)$ model under the Gaussian distribution in each monthly return series. The empirical results indicate that the long memory property in volatility holds and in implies dependencies between distant volatility in Indian stock indices, except the indices CNX-500 and CNX-J. In terms of significant, the findings based on the estimates of FIGARCH $(1, \mathrm{~d}, 1)$ model are consistent with the semiparametric model and AG estimator for the CNX-100, CNX and BSESN indices. On the other hand, the findings of FIGARCH $(1, \mathrm{~d}, 1)$ model are inconsistent with the findings of AG estimator for the CNX-500 and CNX-J indices. Overall, the significance of the FIGARCH $(1, \mathrm{~d}, 1)$ model proves the presence of long memory in volatility of the Indian stock market.

\subsection{Asymmetries}

Table $3 \mathrm{~A}$ reports the results regarding the property of asymmetry on volatilities series of each index. Specifically, panel A reports the findings of asymmetry equations. According to this panel, there is a strong evidence of asymmetries on volatilities, as far as all coefficients are significant. However, $R^{2}$ values are low. Positive news is more important than negative for three out of five indices. Panel B shows the findings for the bootstrap non-parametric test of asymmetry for the null hypothesis that the distribution is symmetric with skewness equal to 0 . The empirical findings show that the null hypothesis of symmetry is rejected in all volatility series. These results are also consistent with the D' Agostino (1970) skewness test. Furthermore, according to the three tests, the property of symmetry is rejected in all volatility series.

Table 3B reports the results regarding the property of asymmetry on correlation series of each index. In specific, panel $\mathrm{A}$ and panel $\mathrm{B}$ report the findings of asymmetry equations. The findings indicate significance in all asymmetric coefficients revealing asymmetries in all correlations. The magnitude of positive and negative news is close to each other. In both directions, news has a negative impact on correlations. Panel $\mathrm{C}$ shows the findings for the bootstrap non-parametric test of asymmetry for the null hypothesis that the distribution of correlations is symmetric with skewness equal to 0 . The empirical findings show that the null hypothesis of symmetry is rejected in all correlation series. These results are also consistent with the D' Agostino (1970) skewness test, as reported in panel D. According to the three tests, the property of symmetry is also rejected in all correlation series.

Table 3C reports the estimates of the asymmetric GARCH-types models. Panel A reports the estimates of AR(1)-EGARCH(1,1) model in each monthly return series. Panel B reports the estimates of AR(1)-GJR-GARCH(1,1) model in each monthly return series. According to panel A, we notice that the coefficient bhta, which implies the presence of persistence in volatility is significant only for the return series of indices CNX-500 and CNX-J. Furthermore, the leverage coefficient delta, which indicates the presence of an asymmetric behavior is not significant in all return series. These parametric results are 
inconsistent with the previous one. According to panel B, we can notice that the estimates of coefficient bhta are in accordance with the estimates of coefficient bhta for the AR(1)-EGARCH(1,1) model. On the other hand, according to the coefficient gamma, which indicates the asymmetric behavior, this is significant only for the CNX index. These results are also inconsistent with non-parametric results, as described in Table 3B.

\subsection{Discontinuity / Jumps}

Table 4 presents the frequency of jumps on volatilities and correlations in panels A and B, respectively. Significant in jumps are evident when the frequency of occurrence of jumps is higher than $50 \%$. Most of volatilities of indices have a significant (in-magnitude) frequency of occurrence of jumps. All correlations indicate highly significant jumps with frequencies of occurrences of jumps higher than $70 \%$.

\subsection{Heterogeneity}

Tables 5A and 5B report results in heterogeneity and jumps of volatilities. According to HAR-J (Table $5 \mathrm{~A})$, heterogeneity is evident on all frequencies. Jumps property is also evident in most of indices. The jumps impact is higher than that of the heterogeneity for most of the Indian stock indices. The overall HAR-J model (both heterogeneity and jumps properties) significance is high enough, with $R^{2}$ values from $23 \%$ to $34 \%$. According to HAR-CJ (Table 5B), jumps coefficients are significant in all three different frequencies; continuous components are significant for a time period of up to 5 months. The impact of jumps components is higher than that of the continuous components of volatilities. Both continuous and jumps components of most of volatilities do positively affect volatilities. This result is expected for the continuous but not for the jumps components. The overall significance of the heterogeneity and jumps for volatilities in the HAR-CJ model is high with $R^{2}$ values from $23 \%$ to $37 \%$.

Tables 5C and 5D report results in heterogeneity and jumps of correlations. According to HAR-J (Table $5 \mathrm{C}$ ), heterogeneity is evident on the 5 - and 20-months frequencies. The jumps property is only evident in the BSESN correlations. The overall HAR-J model (both heterogeneity and jumps properties) significance is not negligible, with $R^{2}$ values from $2 \%$ to $10 \%$. However, the HAR-J model significance is lower for correlations than for volatilities. According to HAR-CJ (Table 5D), the coefficients of jumps and continuous components are significant in all three different frequencies; the latter are more important (higher in magnitude) than the former components. A negative impact of 1-month and 5month continuous as well as 20-months jumps components of correlations. The results for the continuous and jumps components can not provide clear-cut concluding remarks. The overall significance of the heterogeneity and jumps in the HAR-CJ model for correlations is high enough with $R^{2}$ values from $2 \%$ to $16 \%$. 


\section{Concluding remarks}

We examine the properties of realized volatility and correlation series in the Indian stock market. The properties are normality, long-memory, asymmetries, jumps and heterogeneity. Most of realized volatility and correlation series are not normally distributed, with some evidence of persistence. Asymmetries are also evident in both volatilities and correlations. Both jumps and heterogeneity properties are significant; whereas, the former is more significant than the latter. The period of analysis spans from January 2, 2006 to November 30, 2014 and incorporates various stock market booms and crashes.

Table 6 summarises results for all properties of volatilities and correlations of the Indian stock market. Firstly, across all descriptive statistics, non-normality is more evident than normality in both volatilities and correlations. This result is revealed by the skewness and kurtosis values, the CvM normality test and the JB test on volatilities and correlations. Secondly, there is evidence in favour of long memory for both volatilities and correlations. The AG estimator reveals long memory. This is also evident by the significance of the FIGARCH $(1, \mathrm{~d}, 1)$ model. Asymmetries are also significant for both volatilities and correlations. This is evident via the significance of the equations of the asymmetry equations, the bootstrap non-parametric test, the D' Agostino (1970) skewness test, and the significance of the coefficients of the asymmetric GARCH-type (EGARCH, and GJR) models. There are significant jumps in both volatilities and correlations. ${ }^{6}$ Regarding the Indian stock market as a total, jumps property is significant based on the frequency of occurrence of jumps as well as the HAR-J and HAR-CJ models. ${ }^{7}$ Heterogeneity is mostly significant only for volatilities. There is a significant heterogeneity property in volatilities. ${ }^{8}$ In correlations, heterogeneity property is not evident. ${ }^{9}$ Regarding the Indian stock market as a total, heterogeneity property is significant based on the HAR-J and HAR-CJ models only for the volatilities and correlations series. ${ }^{10}$

The empirical findings indicate the importance of realized volatility and correlation estimation for emerging and quite promising markets, such as the Indian stock market. Furthermore, the Indian stock market shares the properties of volatilities and correlations of developed stock markets. This result is promising for the empowerment of the most recent asset and risk management research in emerging markets, like India. The out-of-sample as well as the portfolio behaviour of the properties of realized volatilities and correlations in emerging stock markets may be a future research topic. The findings are relevant for non-speculative funds such as individual investors and pension funds which make decision in a monthly frequency rather than daily frequency. Overall, the results suggest that normality, longmemory, asymmetries, jumps and heterogeneity properties of volatility and correlation series enhance the risk management practices of non-speculative funds in the Indian stock market. Moreover, the resources

\footnotetext{
${ }^{6}$ There is a single exception for the volatility series of the $C N X-100$ index.

${ }^{7}$ There is a single exception for the HAR-J model upon the correlation series.

${ }^{8}$ There are two exceptions for the volatility series of the $C N X-500$ and $C N X-100$ indices.

${ }^{9}$ There are two exceptions for the correlation series with the $C N X$ and $B S E S N$ indices.

${ }^{10}$ There is a single exception for the HAR-J model upon the correlation series.
} 
for economic growth comes from non-speculative and pension funds, if risk can be well measured then the decision can be made efficiently which increases further growth. As far as Indian stock market has the similar properties like the developed world, this study suggest that the use of realized volatility is recognized as the best in asset management for non-speculative funds.

\section{Acknowledgements}

Konstantinos Gkillas (Gillas) gratefully acknowledges research support by General Secretariat for Research and Technology (GSRT) and Hellenic Foundation for Research and Innovation (HFRI). 


\section{References}

[1] H. Akaike, A new look at the statistical model identification. IEEE Transactions on Automatic Control, 19 (1974), 716-723.

[2] C. Alper, E. Fendoglu, B. Saltoglu, MIDAS volatility forecast performance under market stress: Evidence from emerging stock markets. Economics Letters, 117 (2012), 528-532.

[3] K. Amira, A. Taamouti, G. Tsafack, What drives international equity correlations? Volatility or market direction? Journal of International Money and Finance, 30 (2011), 1234-1263.

[4] M. Anand, Determination of volatile pattern of portfolios to invest in Indian stock market. Journal of Portfolio Management, (2014), forthcoming. Available at SSRN: https://ssrn.com/abstract $=1025766$.

[5] T. Andersen, T. Bollerslev, Heterogeneous information arrivals and return volatility dynamics: Uncovering the long-run in high frequency returns. Journal of Finance, 52 (1997), 975-1005.

[6] T. Andersen, T. Bollerslev, F. Diebold, Roughing it up: Including jump components in the measurement, modeling and forecasting of return volatility. Review of Economics and Statistics, 89 (2007), 701-720.

[7] T. Andersen, T. Bollerslev, F. Diebold, H. Ebens, The distribution of stock return volatility. Journal of Financial Economics, 61 (2001), 43-76.

[8] T. Andersen, T. Bollerslev, F. Diebold, P. Labys, The distribution of realized exchange rate volatility. Journal of the American Statistical Association, 96 (2001), 42-55.

[9] D. Andrews, P. Guggenberger, A bias-reduced log-periodogram regression estimator for the longmemory parameter. Econometrica, 71 (2000), 675-712.

[10] A. Atak, G. Kapetanios, A factor approach to realized volatility forecasting in the presence of finite jumps and cross-sectional correlation in pricing errors. Economics Letters, 120 (2013), 224-228.

[11] R.T. Baillie, T. Bollerslev, H.O. Mikkelsen, Fractionally Integrated Generalized Autoregressive Conditional Heteroskedasticity. Journal of Econometrics, 74 (1996), 3-30.

[12] F. Bandi, B. Perron, Long memory and the relation between implied and realized volatility. Journal of Financial Econometrics, 4 (2006), 636-670.

[13] O. Barndorff-Nielsen, N. Shephard, Impact of jumps on returns and realised variances: Econometric analysis of time-deformed Levy processes. Journal of Econometrics, 131 (2006a), 217-252. 
[14] O. Barndorff-Nielsen, N. Shephard, Econometrics of testing for jumps in financial economics using bipower variation. Journal of Financial Econometrics, 4 (2006b), 1-30.

[15] S. Bentes, Measuring persistence in stock market volatility using the FIGARCH approach. Physica A, 408 (2014), $190 \hat{a ̂ 197 . ~}$

[16] S. Bentes, Long memory volatility of gold price returns: How strong is the evidence from distinct economic cycles? Physica A, 443 (2016), 149â160.

[17] S. Bentes, On the relation between implied and realized volatility indices: Evidence from the BRIC countries. Physica A, 482 (2017), 243 â248.

[18] S. Bentes, R. Menezes, On the predictability of realized volatility using Feasible GLS. Journal of Asian Economics, 28 (2013), 58-66.

[19] S. Bentes, R. Menezes, N. Ferreira, On the asymmetric behaviour of stock market volatility: evidence from three countries. International Journal of Academic Research, 5 (2013), 24-32.

[20] S. Bentes, R., Menezes, D.A. Mendes, Long memory and volatility clustering: Is the empirical evidence consistent across stock markets? Physica A, 387 (2008), 3826-3830.

[21] J. Beran, D. Ocker, Volatility of stock-market indexes - An analysis based on SEMIFAR models. Journal of Business and Economic Statistics, 19 (2001), 103-116.

[22] S. Bhaduri, A. Samuel, International equity market integration: The Indian conundrum. Journal of Emerging Market Finance, 8 (2009), 45-66.

[23] R. Bhar, B. Nikolova, Return, volatility spillovers and dynamic correlation in the BRIC equity markets: An analysis using a bivariate EGARCH framework. Global Finance Journal, 19 (2009), $203-218$.

[24] M. Bianconi, J. Yoshino, M. de Sousa, BRIC and the US financial crisis: An empirical investigation of stock and bond markets. Emerging Markets Review, 14 (2013), 76-109.

[25] M. Brandt, F. Diebold, A no-arbitrage approach to range-based estimation of return covariances and correlations. Journal of Business, 79 (2006), 1-13.

[26] S.-M. Chiang, H.-F. Chen, C.-T. Lin, The spillover effects of the sub-prime mortgage crisis and optimum asset allocation in the BRICV stock markets. Global Finance Journal, 24 (2013), 30-43.

[27] R. Chiriac, V. Voev, Modelling and forecasting multivariate realized volatility. Journal of Applied Econometrics, 26 (2011), 922-947. 
[28] K. Christensen, R. Oomen, M. Podolskij, Realised quantile-based estimation of the integrated variance. Journal of Econometrics, 159 (2010), 74-98.

[29] K. Christensen, M. Podolskij, Asymptotic theory of range-based multipower variation. Journal of Financial Econometrics, 10 (2012), 417-456.

[30] M. Clements, A. Galvao, J. Kim, Quantile forecasts of daily exchange rate returns from forecasts of realized volatility. Journal of Empirical Finance, 15 (2008), 729-750.

[31] F. Corsi, A simple approximate long-memory model of realized volatility. Journal of Financial Econometrics, 7 (2009), 174-196.

[32] A. Das, N.R. Kumar, B. Debnath, S. Mandal, Global economic crisis: Causes, impact on Indian economy, agriculture and fisheries. International Journal of Agriculture Sciences, 199 (2012), 221226.

[33] R.B. De Agostino, Transformation to normality of the null distribution of G1. Biometrika, 57 (1970), 679-681.

[34] A. Dixit, S. Yadav, P. Jain, Informational efficiency of implied volatilities of S\&P CNX Nifty index options: A study in Indian securities market. Journal of Advances in Management Research, 7 (2010), 32-57.

[35] J.M. Dufour, D. Pelletier, E. Renault, Short run and long run causality in time series: Inference. Journal of Econometrics, 132 (2006), 337-362.

[36] R.B. Durand, Y. Lan, A. Ng, Conditional beta: Evidence from Asian emerging markets. Global Finance Journal, 22 (2011), 130-153.

[37] N.B. Ferreira, R. Menezes, D.A. Mendes, Asymmetric conditional volatility in international stock markets. Physica A, 382 (2007), 73â80.

[38] J.J. French, A. Naka, Dynamic relationships among equity flows, equity returns and dividends: Behavior of US investors in China and India. Global Finance Journal, 24 (2013), 13-29.

[39] S. Garg, Vipul, Volatility risk premium in Indian options prices. Journal of Futures Markets, 35 (2015), $795-812$.

[40] E. Ghysels, P. Santa-Clara, R. Valkanov, Predicting volatility: Getting the most out of return data sampled at different frequencies. Journal of Econometrics, 131 (2006), 59-95.

[41] C.I. Giannikos, E. Gousgounis, Short sale constraints and dispersion of opinion: Evidence from the Indian equity market. Financial Review, 47 (2012), 115-143. 
[42] L.R. Glosten, R. Jagannathan, D.E. Runkle, Relationship between the expected value and the volatility of the nominal excess return on stocks. The Journal of Finance, 48 (1993), 1779-1801.

[43] C.W.J. Granger, Time series concepts for conditional distributions. Oxford Bulletin of Economics and Statistics, 65 (2003), 689-701.

[44] X. Huang, G. Tauchen, The relative contribution of jumps to total price variance. Journal of Financial Econometrics, 3 (2005), 456-499.

[45] C.M. Jarque, A.K. Bera, Efficient test for normality, homoscedasticity and serial independence of residuals. Economic Letters, 6 (1980), 255-259.

[46] M. Karmakar, Asymmetric volatility and risk-return relationship in the Indian stock market. South Asia Economic Journal, 8 (2007), 99-116.

[47] D. Kumar, Return and volatility transmission between gold and stock sectors: Application of portfolio management and hedging effectiveness. IIMB Management Review, 26 (2014), 5-16.

[48] A.V. Kumar, S. Jaiswal, The Information content of alternate implied volatility models: Case of Indian markets. Journal of Emerging Market Finance, 12 (2013), 293-321.

[49] Y. Liao, The benefit of modeling jumps in realized volatility for risk prediction: Evidence from Chinese mainland stocks. Pacific-Basin Finance Journal, 23 (2013), 25-48.

[50] D. Majumder, Asset pricing model for inefficient markets: Empirical evidence from the Indian market. Reserve Bank of India Occasional Papers, 33 (2012), 65-88.

[51] B. Mandelbrot, L. Hudson, The Misbehavior of Markets, Basic Books (2009).

[52] M. Martens, D. van Dijk, Measuring volatility with the realized range. Journal of Econometrics, 138 (2007), 181-207.

[53] R. Monhan, Global financial crisis and key risks: Impact on India and Asia. Remarks (IMF-FSF High Level Meeting on the Recent Financial Turmoil and Policy Responses at Washington D.C.) (2009).

[54] D.B. Nelson, Conditional heteroscedasticity in asset returns: a new approach. Econometrica, 59 (1991), 347-370.

[55] A. Pandey, The extreme value volatility estimators and their empirical performance in Indian capital markets. Working paper, Indian Institute of Management (2002).

[56] M. Parkinson, The extreme value method for estimating the variance of the rate of return. Journal of Business, 53 (1980), 6-15. 
[57] A. Prasad, C.P. Reddy, Global financial crisis and its impact on India. Journal of Social Sciences, 13 (2009), 1-5.

[58] D.N. Rao, G. Kaur, Effect of global economic meltdown on commodities markets: An empirical study of select agricultural commodities traded in NCDEX. SSRN Working paper, (2009).

[59] B. Sevi, An empirical analysis of the downside risk-return trade-off at daily frequency. Economic Modelling, 31 (2013), 189-197.

[60] M. Soucek, N. Todorova, Realized volatility transmission: The role of jumps and leverage effects. Economics Letters, 122 (2014), 111-115.

[61] N. Todorova, Volatility estimators based on daily price ranges versus the realized range. Applied Financial Economics, 22 (2012), 215-229.

[62] N. Todorova, M. Soucek, The impact of trading volume, number of trades and overnight returns on forecasting the daily realized range. Economic Modelling, 36 (2014), 332-340.

[63] T. Tripathy, L.A. Gil-Alana, Suitability of volatility models for forecasting stock market returns: A study on the Indian national stock exchange. American Journal of Applied Sciences, 7 (2010), 1487-1494.

[64] T. Tripathy, L.A. Gil-Alana, Modelling time-varying volatility in the Indian stock returns: Some empirical evidence. Review of Development Finance, 5 (2015), 91-97. 


\section{Tables}

\begin{tabular}{|c|c|c|c|c|c|}
\hline & \multicolumn{5}{|c|}{ Table 1A. Distributional properties } \\
\hline & Mean & Skew. & Kurt. & CVM-test & JB-test \\
\hline & \multicolumn{5}{|c|}{ Panel A. Returns } \\
\hline$C N X-500$ & 0.812 & -8.204 & 72.555 & $3.341(2.82 \mathrm{e}+13)$ & $9.669(0.008)^{* *}$ \\
\hline$C N X-100$ & 0.830 & -8.196 & 72.480 & $3.283(1.42 \mathrm{e}+12)$ & $14.048(0.000)^{* *}$ \\
\hline$C N X-J$ & 0.894 & -7.862 & 68.555 & $2.802(699.330)$ & $14.340(0.000)^{* *}$ \\
\hline$C N X$ & 0.832 & -8.269 & 73.346 & $3.418(1.76 \mathrm{e}+15)$ & $15.603(4.09 \mathrm{e}-04)^{* *}$ \\
\hline \multirow[t]{2}{*}{$B S E S N$} & 0.952 & -8.440 & 75.346 & $3.804(1.48 \mathrm{e}+25)$ & $12.216(0.002)^{* *}$ \\
\hline & \multicolumn{5}{|c|}{ Panel B. Volatilities } \\
\hline$C N X-500$ & $3.52 \mathrm{e}-3$ & 2.715 & 11.172 & $1.658(1.52 \mathrm{e}-9)^{* *}$ & $603.244(0.000)^{* *}$ \\
\hline$C N X-100$ & $4.15 \mathrm{e}-3$ & 2.949 & 13.393 & $1.678(1.81 \mathrm{e}-9)^{* *}$ & $764.320(0.000)^{* *}$ \\
\hline$C N X-J$ & $5.49 \mathrm{e}-3$ & 2.554 & 10.305 & $1.684(1.93 \mathrm{e}-9)^{* *}$ & $287.432(0.000)^{* *}$ \\
\hline$C N X$ & $5.34 \mathrm{e}-3$ & 2.900 & 13.353 & $1.757(4.06 \mathrm{e}-9) * *$ & $904.367(0.000)^{* *}$ \\
\hline$B S E S N$ & $4.00 \mathrm{e}-3$ & 2.771 & 12.337 & $1.597(9.40 \mathrm{e}-10)^{* *}$ & $1,015.101(0.000)^{* *}$ \\
\hline
\end{tabular}

Notes. Table 1A reports the descriptive statistics of returns (panel A), and volatilities (panel B) for the five Indian stock indices. In brackets, there are p-values. ${ }^{* *}$ and * reveal significance in the $5 \%$ and $10 \%$ significance level, respectively. 
Table 1B. Distributional properties - Correlations

\begin{tabular}{ccrrr}
\hline$C N X-500$ & $C N X-100$ & $C N X-J$ & CNX
\end{tabular}

\begin{tabular}{|c|c|c|c|c|c|}
\hline$C N X-500$ & - & & & & \\
\hline$C N X-100$ & 0.808 & - & & & \\
\hline$C N X-J$ & 0.696 & 0.653 & - & & \\
\hline$C N X$ & 0.725 & 0.713 & 0.566 & - & \\
\hline \multirow[t]{2}{*}{$B S E S N$} & 0.720 & 0.705 & 0.564 & 0.638 & - \\
\hline & \multicolumn{5}{|c|}{ Panel B. Skewness } \\
\hline$C N X-500$ & - & & & & \\
\hline$C N X-100$ & 2.026 & - & & & \\
\hline$C N X-J$ & 1.140 & 0.935 & - & & \\
\hline$C N X$ & 1.353 & 1.396 & 0.027 & - & \\
\hline \multirow[t]{2}{*}{$B S E S N$} & 0.932 & 0.912 & 0.247 & -0.105 & - \\
\hline & \multicolumn{5}{|c|}{ Panel C. Kurtosis } \\
\hline$C N X-500$ & - & & & & \\
\hline$C N X-100$ & 10.573 & - & & & \\
\hline$C N X-J$ & 6.738 & 6.239 & - & & \\
\hline$C N X$ & 6.825 & 7.746 & 3.623 & - & \\
\hline \multirow[t]{2}{*}{$B S E S N$} & 8.870 & 9.093 & 5.349 & 5.438 & - \\
\hline & \multicolumn{5}{|c|}{ Panel D. CVM-test } \\
\hline$C N X-500$ & - & & & & \\
\hline$C N X-100$ & $0.349(8.93 \mathrm{e}-5)^{* *}$ & - & & & \\
\hline$C N X-J$ & $0.120(0.059)^{*}$ & $0.107(0.088)^{*}$ & - & & \\
\hline$C N X$ & $0.289(4.29 \mathrm{e}-4)^{* *}$ & $0.403(2.34 \mathrm{e}-5)^{* *}$ & $0.036(0.758)$ & - & \\
\hline \multirow[t]{2}{*}{$B S E S N$} & $0.313(2.27 \mathrm{e}-4)^{* *}$ & $0.345(9.85 \mathrm{e}-5)^{* *}$ & $0.139(0.032)^{* *}$ & $0.284(4.84 \mathrm{e}-4)^{* *}$ & - \\
\hline & \multicolumn{5}{|c|}{ Panel E. JB-test } \\
\hline$C N X-500$ & - & & & & \\
\hline$C N X-100$ & $526.164^{* *}$ & - & & & \\
\hline$C N X-J$ & $213.281^{* *}$ & $187.531^{* *}$ & - & & \\
\hline$C N X$ & $597.963^{* *}$ & $357.622^{* *}$ & $191.451^{* *}$ & - & \\
\hline$B S E S N$ & $512.161^{* *}$ & $550.276^{* *}$ & $234.018^{* *}$ & $552.695^{* *}$ & - \\
\hline
\end{tabular}

Notes. Table 1B reports the descriptive statistics of correlations between the five Indian stock indices. 
Panel A reports their mean values; panel B reports skewness values; panel C reports the kurtosis values; panel D reports the CVM-test for normality; and panel E reports the JB-test for normality. In brackets, there are p-values. ${ }^{* *}$ and $*$ reveal significance in the $5 \%$ and $10 \%$ significance level, respectively. 
Table 2A. Long-memory property

\begin{tabular}{cc|cccc} 
& \multicolumn{4}{|c}{ Correlations $\left(R C_{t}^{R R}\right)$} \\
& Volatility $\left(R V_{t}^{R R}\right)$ & \multicolumn{4}{c}{} \\
\cline { 2 - 6 }$C N X-500$ & 0.206 & $C N X-500$ & $C N X-100$ & $C N X-J$ & $C N X$ \\
$C N X-100$ & 0.247 & 0.247 & - & - \\
$C N X-J$ & 0.232 & 0.206 & 0.247 & \\
$C N X$ & 0.253 & 0.247 & 0.250 & 0.242 & - \\
$B S E S N$ & 0.269 & 0.208 & 0.248 & 0.252 & 0.255 \\
\hline
\end{tabular}

Notes. Table 2A entries report the long-memory estimates (d-values) for the realised ranges and realised range correlations. All estimates are statistically significant. SE are available upon request. 
Table 2B. Estimation results of FIGARCH model for long memory

\begin{tabular}{cccccc} 
& \multicolumn{1}{c}{$c$} & $\omega$ & $\beta$ & $\delta$ & $\phi$ \\
\cline { 2 - 6 }$C N X-500$ & $0.003^{*}$ & $1.34 \mathrm{e}-4$ & $0.742^{*}$ & 0.884 & 0.334 \\
$C N X-100$ & $0.003^{*}$ & $-9.02 \mathrm{e}-6$ & $0.587^{*}$ & $0.458^{* *}$ & 0.161 \\
$C N X-J$ & $0.004^{*}$ & $1.65 \mathrm{e}-5^{* *}$ & $0.681^{*}$ & 0.790 & 0.296 \\
$C N X$ & $0.003^{*}$ & $-1.73 \mathrm{e}-5$ & $0.589^{*}$ & $0.461^{* *}$ & 0.084 \\
$B S E S N$ & $0.003^{*}$ & $3.75 \mathrm{e}-6$ & $0.540^{*}$ & $0.517^{*}$ & -0.016 \\
\cline { 2 - 6 }
\end{tabular}

Notes. Table 2B reports the FIGARCH(1,d,1) estimates for the four Indian stock indices. The model was selected according to the Akaike (1974) information criterion. ** and * reveal significance in the $5 \%$ and $10 \%$ significance level, respectively. 


\begin{tabular}{|c|c|c|c|}
\hline & \multicolumn{3}{|c|}{ Table 3A. Asymmetries - Volatilities } \\
\hline & \multicolumn{3}{|c|}{ Panel A. $b$ - coefficient } \\
\hline & $\beta$ & $\gamma$ & $R^{2}$ \\
\hline$C N X-500$ & $5.06 \mathrm{e}-3^{* *}$ & $9.23 \mathrm{e}-4^{* *}$ & 0.026 \\
\hline$C N X-100$ & $3.23 \mathrm{e}-3^{* *}$ & $-2.30 \mathrm{e}-4^{* *}$ & $7.03 \mathrm{e}-3$ \\
\hline$C N X-J$ & $4.36 \mathrm{e}-4^{* *}$ & $5.71 \mathrm{e}-3^{* *}$ & $6.03 \mathrm{e}-3$ \\
\hline$C N X$ & $9.66 \mathrm{e}-3^{* *}$ & $-2.37 \mathrm{e}-3^{* *}$ & 0.033 \\
\hline \multirow[t]{3}{*}{$B S E S N$} & $3.94 \mathrm{e}-3^{* *}$ & $-4.69 \mathrm{e}-3^{* *}$ & 0.017 \\
\hline & \multicolumn{3}{|c|}{ Panel B. Test for Asymmetry } \\
\hline & Bootstrap non-parametric test & De Agostino skewness test & \\
\hline$C N X-500$ & $149.537^{* *}$ & $7.102^{* *}$ & \\
\hline$C N X-100$ & $130.128^{* *}$ & $7.339^{* *}$ & \\
\hline$C N X-J$ & $176.882^{* *}$ & $6.752^{* *}$ & \\
\hline$C N X$ & $126.809^{* *}$ & $7.473^{* *}$ & \\
\hline$B S E S N$ & $116.444^{* *}$ & $7.521^{* *}$ & \\
\hline
\end{tabular}

Notes. Table 3A entries report the $R^{2}$ and the asymmetric ( $b$ - and $g$-) coefficients from the asymmetric regression for volatilities.

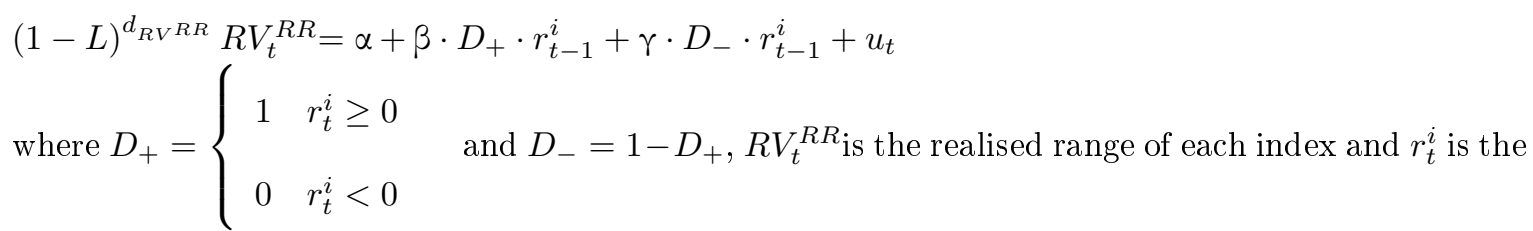
returns series of the $i$ respective indicator. ${ }^{* *}$ and $*$ reveals significance in the $5 \%$ and $10 \%$ significance level. $^{11}$

\footnotetext{
${ }^{11}$ The heteroscedasticity and autocorrelation consistent (Newey-West) SE ( $\left.N W S E\right)$ are available upon request.
} 


\begin{tabular}{|c|c|c|c|c|}
\hline & \multicolumn{4}{|c|}{ Table 3B. Asymmetries - Correlations } \\
\hline & $C N X-500$ & $C N X-100$ & $C N X-J$ & $C N X$ \\
\hline & \multicolumn{4}{|c|}{ Panel A. $\beta$ - coefficient } \\
\hline$C N X-500$ & - & & & \\
\hline$C N X-100$ & $-0.065^{* *}$ & - & & \\
\hline$C N X-J$ & $0.016^{* *}$ & $0.012^{* *}$ & - & \\
\hline$C N X$ & $-0.068^{* *}$ & $-0.078^{* *}$ & $-0.014^{* *}$ & - \\
\hline \multirow[t]{2}{*}{$B S E S N$} & $-0.037^{* *}$ & $-0.023^{* *}$ & $-0.029^{* *}$ & $-0.050^{* *}$ \\
\hline & \multicolumn{4}{|c|}{ Panel B. $\gamma$ - coefficient } \\
\hline$C N X-500$ & - & & & \\
\hline$C N X-100$ & $-0.012^{* *}$ & - & & \\
\hline$C N X-J$ & $-0.055^{* *}$ & $-0.055^{* *}$ & - & \\
\hline$C N X$ & $-0.016^{* *}$ & $-4.84 \mathrm{e}-4$ & $-0.043^{* *}$ & - \\
\hline \multirow[t]{2}{*}{$B S E S N$} & $-0.061^{* *}$ & $-0.063^{* *}$ & $-0.069^{* *}$ & $-0.051^{* *}$ \\
\hline & \multicolumn{4}{|c|}{ Panel C. Bootstrap non-parametric test } \\
\hline$C N X-500$ & - & & & \\
\hline$C N X-100$ & $-110.790^{* *}$ & - & & \\
\hline$C N X-J$ & $-136.921^{* *}$ & $-128.178^{* *}$ & - & \\
\hline$C N X$ & $-104.732^{* *}$ & $-88.145^{* *}$ & $-123.440^{* *}$ & - \\
\hline \multirow[t]{2}{*}{$B S E S N$} & $-132.210^{* *}$ & $-120.821^{* *}$ & $-193.464^{* *}$ & $120.468^{* *}$ \\
\hline & \multicolumn{4}{|c|}{ Panel D. De Agostino skewness test } \\
\hline$C N X-500$ & - & & & \\
\hline$C N X-100$ & $-6.829^{* *}$ & - & & \\
\hline$C N X-J$ & $-5.992^{* *}$ & $-5.848^{* *}$ & - & \\
\hline$C N X$ & $-6.926^{* *}$ & $-6.266^{* *}$ & $-5.817 * *$ & - \\
\hline$B S E S N$ & $-7.407 * *$ & $-7.487^{* *}$ & $-6.451^{* *}$ & $-7.491^{* *}$ \\
\hline
\end{tabular}

Notes. Table 3B reports the $b$ - and $g$ - coefficients of the asymmetric regression for the realised correlation $\left(R C_{t}^{R R}\right)$ estimates between the five Indian stock indices in panel A and B accordingly.

$$
\begin{aligned}
& (1-L)^{d_{R C} R R} R C_{t}^{R R}=\alpha+\beta \cdot D_{+} \cdot R C_{t-1}^{R R}+\gamma \cdot D_{-} \cdot R C_{t-1}^{R R}+u_{t} \\
& \text { where } D_{+}=\left\{\begin{array}{cc}
1 & r_{t}^{i} \geq 0 \\
0 & r_{t}^{i}<0
\end{array} \quad \text { and } D_{-}=1-D_{+} .\right.
\end{aligned}
$$

$R C_{t}^{R R}$ is the realised range correlation. ${ }^{* *}$ and $*$ reveals significance in the $5 \%$ and $10 \%$ significance level. ${ }^{12}$

\footnotetext{
${ }^{12}$ The heteroscedasticity and autocorrelation consistent (Newey-West) SE (NW SE) are available upon request.
} 
Table 3C. Estimation results of asymmetric GARCH-type models

\begin{tabular}{|c|c|c|c|c|c|c|}
\hline$c$ & $\phi 1$ & $\omega$ & $\alpha$ & $\beta$ & $\delta$ & $\mathrm{R}^{2}$ \\
\hline
\end{tabular}

Panel A. AR(1)-EGARCH(1,1)

\begin{tabular}{ccc|ccccc}
$C N X-500$ & $0.003^{*}$ & $-0.384^{*}$ & $-6.926^{*}$ & $0.980^{*}$ & $0.295^{*}$ & -0.017 & 0.077 \\
$C N X-100$ & $0.001^{*}$ & $-0.357^{*}$ & $-8.552^{*}$ & $0.854^{*}$ & 0.080 & -0.043 & 0.098 \\
$C N X-J$ & $0.006^{*}$ & -0.187 & $-6.482^{*}$ & $1.300^{*}$ & $0.359^{*}$ & -0.030 & 0.041 \\
$C N X$ & $0.003^{*}$ & $-0.391^{*}$ & $-9.600^{*}$ & $0.683^{*}$ & -0.061 & -0.090 & 0.100 \\
$B S E S N$ & $0.003^{*}$ & $-0.436^{*}$ & $-7.998^{*}$ & $0.900^{*}$ & 0.146 & -0.078 & 0.106 \\
\cline { 2 - 8 } & \multicolumn{7}{c}{ Panel B. AR(1)-GJR-GARCH(1,1) } \\
CNX-500 & $0.005^{*}$ & $-0.327^{*}$ & $3.29 \mathrm{e}-5$ & 0.146 & $0.641^{*}$ & 0.065 & 0.102 \\
$C N X-100$ & $0.004^{*}$ & $-0.423^{*}$ & $1.28 \mathrm{e}-4^{*}$ & 0.397 & -0.043 & 0.288 & 0.089 \\
$C N X-J$ & $0.005^{*}$ & -0.132 & $2.21 \mathrm{e}-5$ & $0.313^{* *}$ & $0.658^{*}$ & -0.087 & 0.034 \\
$C N X$ & $0.003^{*}$ & $-0.352^{*}$ & $2.52 \mathrm{e}-4^{*}$ & 0.340 & $-0.433^{* *}$ & $0.613^{* *}$ & 0.106 \\
$B S E S N$ & $0.003^{*}$ & $-0.510^{* *}$ & $1.13 \mathrm{e}-3^{*}$ & $0.200^{* *}$ & -0.068 & 0.247 & 0.094 \\
\cline { 2 - 7 }
\end{tabular}

Notes. Table 3C reports the asymmetric GARCH-types estimates for the four Indian stock indices. Panel A reports the estimates of an $\operatorname{AR}(1)$-EGARCH$(1,1,1)$. Panel B reports the estimates of an AR(1)GJR-GARCH(1,1,1). The model was selected according to the Akaike (1974) information criterion. ** and * reveals significance in the $5 \%$ and $10 \%$ significance level. 
Table 4. Frequency of Jumps

\begin{tabular}{cc|cccc} 
& \multirow{2}{*}{ Volatility } & \multicolumn{4}{|c}{ Correlations } \\
& & $C N X-500$ & $C N X-100$ & $C N X-J$ & $C N X$ \\
\cline { 2 - 6 }$C N X-500$ & 0.393 & - & & & \\
$C N X-100$ & 0.452 & $0.880^{*}$ & - & - & \\
$C N X-J$ & $0.583^{*}$ & $0.831^{*}$ & $0.795^{*}$ & $0.723^{*}$ & - \\
$C N X$ & $0.595^{*}$ & $0.867^{*}$ & $0.795^{*}$ & $0.687^{*}$ & $0.783^{*}$ \\
\hline$B S E S N$ & $0.510^{*}$ & $0.819^{*}$ & $0.843^{*}$ & 0.61
\end{tabular}

Notes. Table 4 reports the frequency of jumps occurence in volatilities and correlations. Jumps series is significant (indicated by *) if the frequency of occurence of jumps is higher than $50 \%$. 
Table 5A. Heterogeneity and Jumps (HAR-J model) - Volatilities

\begin{tabular}{cccccc}
\cline { 2 - 6 } & $\beta_{1 M}$ & $\beta_{5 M}$ & $\beta_{20 M}$ & $\gamma_{J}$ & $R^{2}$ \\
\cline { 2 - 6 }$C N X-500$ & $0.411^{* *}$ & $0.136^{* *}$ & $0.024^{*}$ & $5.754^{*}$ & 0.290 \\
$C N X-100$ & $0.458^{* *}$ & $0.132^{* *}$ & 0.013 & -0.024 & 0.248 \\
$C N X-J$ & $0.328^{* *}$ & $0.215^{* *}$ & $0.053^{* *}$ & $3.523^{* *}$ & 0.282 \\
$C N X$ & $0.438^{* *}$ & $0.126^{* *}$ & $-0.019^{*}$ & $2.85 \mathrm{e}-3$ & 0.228 \\
$B S E S N$ & $0.554^{* *}$ & $0.109^{* *}$ & $-7.65 \mathrm{e}-3$ & $-1.501^{* *}$ & 0.343 \\
\cline { 2 - 6 }
\end{tabular}

Notes. Table $5 \mathrm{~A}$ entries report $R^{2}$ and the $\beta_{1 M}, \beta_{5 M}, \beta_{20 M}$ and $\gamma_{J}$ regression coefficient estimates from the HAR-J model:

$$
R V_{t}^{R R}=\beta_{0}+\beta_{1 M} R V_{t-1, t}^{R R}+\beta_{5 M} R V_{t-5, t}^{R R}+\beta_{20 M} R V_{t-20, t}^{R R}+\gamma_{J} J_{t-1, t}^{R V^{R R}}
$$

and dependent variable is volatilities. ${ }^{* *}$ and ${ }^{*}$ reveals significance in the $5 \%$ and $10 \%$ significance level. ${ }^{13}$

\footnotetext{
${ }^{13}$ The heteroscedasticity and autocorrelation consistent (Newey-West) SE (NW SE) are available upon request.
} 
Table 5B. Heterogeneity and Jumps (HAR-CJ model) - Volatilities

\begin{tabular}{cccccccc}
\cline { 2 - 7 } & $\beta_{C_{1 M}}$ & $\beta_{C_{5 M}}$ & $\beta_{C_{20 M}}$ & $\gamma_{J_{1 M}}$ & $\gamma_{J_{5 M}}$ & $\gamma_{J_{20 M}}$ & $R^{2}$ \\
\cline { 2 - 7 }$C N X-500$ & 7.253 & -0.247 & 6.114 & $0.397^{* *}$ & $0.101^{* *}$ & $7.98 \mathrm{e}-4$ & 0.363 \\
$C N X-100$ & 0.387 & $1.049^{*}$ & 2.244 & 0.434 & $0.098^{* *}$ & $-5.25 \mathrm{e}-3^{* *}$ & 0.264 \\
$C N X-J$ & $4.965^{* *}$ & $-3.074^{* *}$ & 0.051 & $0.395^{* *}$ & $0.223^{* *}$ & 0.016 & 0.329 \\
$C N X$ & $0.404^{*}$ & $-0.123^{* *}$ & 0.291 & $0.435^{* *}$ & $0.136^{* *}$ & $-0.028^{*}$ & 0.232 \\
$B S E S N$ & $-1.190^{*}$ & $1.935^{* *}$ & 3.028 & $0.546^{* *}$ & $0.085^{* *}$ & $-0.053^{* *}$ & 0.367 \\
\hline
\end{tabular}

Notes. Table $5 \mathrm{~B}$ entries report $R^{2}$ and the $\beta_{C_{1 M}}, \beta_{C_{5 M}}, \beta_{C_{20 M}}, \gamma_{J_{1 M}}, \gamma_{J_{5 M}}$ and $\gamma_{J_{20 M}}$ regression coefficient estimates from the HAR-CJ model:

$R V_{t}^{R R}=\left\{\begin{array}{c}\beta_{0}+\beta_{C_{1 M}} C_{t-1, t}^{R V^{R R}}+\beta_{C_{5 M}} C_{t-5, t}^{R V^{R R}}+\beta_{C_{20 M}} C_{t-20, t}^{R V^{R R}}+ \\ \gamma_{J_{1 M}} J_{t-1, t}^{R V^{R R}}+\gamma_{J_{5 M}} J_{t-5, t}^{R V^{R R}}+\gamma_{J_{20 M}} J_{t-20, t}^{R V^{R R}}+\epsilon_{t}\end{array}\right.$

and dependent variable is the realised range (volatility) series. ${ }^{* *}$ and $*$ reveals significance in the $5 \%$ and $10 \%$ significance level. ${ }^{14}$

\footnotetext{
${ }^{14}$ The heteroscedasticity and autocorrelation consistent (Newey-West) SE (NW SE) are available upon request.
} 


\begin{tabular}{|c|c|c|c|}
\hline$C N X-500$ & $C N X-100$ & $C N X-J$ & $C N X$ \\
\hline \multicolumn{4}{|c|}{ Panel A. $\beta_{1 M}$} \\
\hline - & & & \\
\hline 1.295 & - & & \\
\hline 1.1671 & -0.330 & - & \\
\hline 2.630 & 2.948 & 1.679 & - \\
\hline$-0.031 *$ & $0.125 * *$ & $-0.053 * *$ & $0.097 * *$ \\
\hline
\end{tabular}

Panel B. $\beta_{5 M}$

\begin{tabular}{|c|c|c|c|c|}
\hline$C N X-500$ & - & & & \\
\hline$C N X-100$ & $-0.091 * *$ & - & & \\
\hline$C N X-J$ & $5.29 \mathrm{e}-3$ & $0.042 * *$ & - & \\
\hline$C N X$ & $-5.61 e-3$ & $-0.015^{*}$ & $0.125 * *$ & - \\
\hline \multirow[t]{2}{*}{$B S E S N$} & $-0.085 * *$ & $-0.101 * *$ & $0.071 * *$ & $-0.114^{* *}$ \\
\hline & \multicolumn{4}{|c|}{ Panel C. $\beta_{20} M$} \\
\hline$C N X-500$ & - & & & \\
\hline$C N X-100$ & $0.053 * *$ & - & & \\
\hline$C N X-J$ & $0.018 * *$ & $-7.03 e-3$ & - & \\
\hline$C N X$ & $0.103 * *$ & $0.054 *$ & $8.10 e-4$ & - \\
\hline$B S E S N$ & $0.133 * *$ & $0.103 * *$ & $0.082 * *$ & $0.113^{* *}$ \\
\hline
\end{tabular}

Panel D. $\gamma_{J}$

$$
\begin{gathered}
C N X-500 \\
C N X-100 \\
C N X-J \\
C N X
\end{gathered}
$$$$
\text { BSESN }
$$

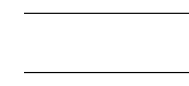

$-1.495$

$$
-1.160
$$$$
0.310
$$$$
-2.857
$$$$
-3.182
$$$$
-1.637
$$

$0.075 *$

$-0.142 * *$

$0.330^{* *}$

$-0.072$

Panel E. $R^{2}$

$$
\begin{gathered}
C N X-500 \\
C N X-100 \\
C N X-J \\
C N X
\end{gathered}
$$$$
B S E S N
$$

$\frac{0.075 *}{-}$

Notes. Table $5 \mathrm{C}$ reports the $\beta_{1 M}, \beta_{5 M}$ and $\beta_{20 M}$ coefficients and $R^{2}$ of the HAR-J model in panels A, $\mathrm{B}, \mathrm{C}$ and D accordingly.

$$
R C_{t}^{R R}=\beta_{0}+\beta_{1 M} R C_{t-1, t}^{R R}+\beta_{5 M} R C_{t-5, t}^{R R}+\beta_{20 M} R C_{t-20, t}^{R R}+\gamma_{J} J_{t-1, t}^{R C^{R R}}
$$

where $J_{t}^{R C^{R R}}$ is the jump component series of the realised range correlation series. $* *$ and $*$ reveals significance in the $5 \%$ and $10 \%$ significance level. ${ }^{15}$

\footnotetext{
${ }^{15}$ The heteroscedasticity and autocorrelation consistent (Newey-West) SE ( $N W S E$ ) are available upon request.
} 


\begin{tabular}{|c|c|c|c|c|}
\hline \multirow{3}{*}{$C N X-500$} & \multirow{2}{*}{\multicolumn{4}{|c|}{ Panel A. $\beta_{C_{1 M}}$}} \\
\hline & & & & \\
\hline & \multicolumn{2}{|l|}{-} & & \\
\hline$C N X-100$ & $-0.245 * *$ & \multicolumn{2}{|l|}{-} & \\
\hline$C N X-J$ & $-0.090^{* *}$ & $-0.140^{* *}$ & - & \\
\hline$C N X$ & $-0.244 * *$ & $-0.251 * *$ & -0.010 & - \\
\hline \multirow[t]{2}{*}{ BSESN } & -0.036 & $-0.05 .3^{*}$ & $0.193 * *$ & O. $135 * *$ \\
\hline & \multicolumn{4}{|c|}{ Panel B. $\beta_{C_{5} M}$} \\
\hline$C N X-500$ & - & & & \\
\hline$C N X-100$ & $-0.177 * *$ & - & & \\
\hline$C N X-J$ & $-0.183^{* *}$ & $-0.110 * *$ & - & \\
\hline$C N X$ & $4.73 e-3$ & $0.060 * *$ & $0.065 * *$ & - \\
\hline \multirow[t]{2}{*}{ BSESN } & $-0.430^{* *}$ & $-0.408 * *$ & $-0.448 * *$ & $-0.335 * *$ \\
\hline & \multicolumn{4}{|c|}{ Panel C. $\beta_{C_{20} M}$} \\
\hline$C N X-500$ & - & & & \\
\hline$C N X-100$ & $0.074^{* *}$ & - & & \\
\hline$C N X-J$ & $0.096^{* *}$ & $0.027^{* *}$ & - & \\
\hline$C N X$ & $0.217^{* *}$ & $0.167^{* *}$ & -0.028 & - \\
\hline \multirow[t]{2}{*}{ BSESN } & $0.106 * *$ & $0.085 * *$ & $0.108 * *$ & $0.321 * *$ \\
\hline & \multicolumn{4}{|c|}{ Panel D. $\gamma J_{1} M$} \\
\hline$C N X-500$ & - & & & \\
\hline$C N X-100$ & $2.80 \mathrm{Oe}-4^{* *}$ & - & & \\
\hline$C N X-J$ & $2.92 e-4^{* *}$ & $4.01 e-4 * *$ & - & \\
\hline$C N X$ & $2.05 e-4 * *$ & $-8.42 e-5 * *$ & $1.10 e-4 * *$ & - \\
\hline \multirow[t]{2}{*}{$B S E S N$} & $2.46 e-4^{* *}$ & $2.42 \mathrm{e}-4 * *$ & $-4.69 e-5 * *$ & $-2.22 e-4 * *$ \\
\hline & \multicolumn{4}{|c|}{ Panel E. $\gamma J_{5} M$} \\
\hline$C N X-500$ & - & & & \\
\hline$C N X-100$ & $5.46 e-3^{* *}$ & - & & \\
\hline$C N X-J$ & $5.62 \mathrm{e}-3^{* *}$ & $3.75 e-4 * *$ & - & \\
\hline$C N X$ & $-3.83 e-5 * *$ & $-1.34 \mathrm{e}-4 * *$ & $5.64 \mathrm{e}-5^{* *}$ & - \\
\hline \multirow[t]{2}{*}{ BSESN } & $1.62 e-3^{* *}$ & $1.27 e-3^{* *}$ & $1.37 \mathrm{e}-3^{* *}$ & $5.99 e-4^{* *}$ \\
\hline & \multicolumn{4}{|c|}{ Panel F. $\gamma_{J_{20} M}$} \\
\hline$C N X-500$ & - & & & \\
\hline$C N X-100$ & $-2.38 \mathrm{e}-4^{* *}$ & - & & \\
\hline$C N X-J$ & $-2.68 \mathrm{e}-4 * *$ & $-2.17 \mathrm{e}-4 * *$ & - & \\
\hline$C N X$ & $-5.68 \mathrm{e}-4^{* *}$ & $-2.75 e-4 * *$ & $-9.52 e-5 * *$ & - \\
\hline \multirow[t]{2}{*}{ BSESN } & $-2.99 e-4 * *$ & $-1.51 \mathrm{e}-4^{* *}$ & $-2.62 e-4 * *$ & $-7.02 e-4 * *$ \\
\hline & \multicolumn{4}{|c|}{ Panel G. $R^{2}$} \\
\hline$C N X-500$ & - & & & \\
\hline$C N X-100$ & 0.093 & - & & \\
\hline$C N X-J$ & 0.099 & 0.083 & - & \\
\hline$C N X$ & 0.097 & 0.085 & 0.020 & - \\
\hline$B S E S N$ & 0.134 & O. 114 & 0.164 & 0.100 \\
\hline
\end{tabular}

Notes. Table $5 \mathrm{D}$ reports the $\beta_{C_{1 M}}, \beta_{C_{5 M}}, \beta_{C_{20} M}, \gamma_{J_{1 M}}, \gamma_{J_{5 M}}$ and $\gamma_{J_{20 M}}$ coefficients and $R^{2}$ of the

HAR-CJ model in panels A, B, C, D, E, F and G accordingly.

$R C_{t}^{R R}=\left\{\begin{array}{c}\beta_{0}+\beta_{C_{1 M}} C_{t-1, t}^{R C^{R R}}+\beta_{C_{5 M}} C_{t-5, t}^{R C^{R R}}+\beta_{C_{20 M}} C_{t-20, t}^{R C^{R R}}+ \\ \gamma_{J_{1 M}} J_{t-1, t}^{R C^{R R}}+\gamma_{J_{5 M}} J_{t-5, t}^{R C^{R R}}+\gamma_{J_{20 M}} J_{t-20, t}^{R C^{R R}}+\epsilon_{t}\end{array}\right.$

$* *$ and ${ }^{*}$ reveals significance in the $5 \%$ and $10 \%$ significance level. ${ }^{16}$

\footnotetext{
${ }^{16}$ The heteroscedasticity and autocorrelation consistent (Newey-West) SE ( $\left.N W S E\right)$ are available upon request.
} 
Table 6. Summarized results

\begin{tabular}{|c|c|c|c|c|c|c|}
\hline & $C N X-500$ & $C N X-100$ & $C N X-J$ & $C N X$ & $B S E S N$ & India \\
\hline \multicolumn{7}{|c|}{ Panel A. Volatilities } \\
\hline Non-normality & $\sqrt{ }$ & $\checkmark$ & $\sqrt{ }$ & $\checkmark$ & $\sqrt{ }$ & $\sqrt{ }$ \\
\hline Long-memory & $\sqrt{ }$ & $\checkmark$ & $\checkmark$ & $\checkmark$ & $\checkmark$ & $\checkmark$ \\
\hline - FIGARCH & - & $\checkmark$ & - & $\checkmark$ & $\sqrt{ }$ & $\sqrt{ }$ \\
\hline Asymmetry & $\sqrt{ }$ & $\checkmark$ & $\checkmark$ & $\sqrt{ }$ & $\sqrt{ }$ & $\sqrt{ }$ \\
\hline - EGARCH & - & - & - & - & - & - \\
\hline - GJR-GARCH & - & - & - & - & $\sqrt{ }$ & - \\
\hline - Frequency & - & - & $\checkmark$ & $\checkmark$ & $\sqrt{ }$ & $\sqrt{ }$ \\
\hline - HAR-J & $\sqrt{ }$ & - & $\sqrt{ }$ & - & $\sqrt{ }$ & $\sqrt{ }$ \\
\hline - HAR-CJ & $\sqrt{ }$ & $\sqrt{ }$ & $\sqrt{ }$ & $\checkmark$ & $\sqrt{ }$ & $\sqrt{ }$ \\
\hline Jumps & $\sqrt{ }$ & - & $\checkmark$ & $\checkmark$ & $\sqrt{ }$ & $\checkmark$ \\
\hline - HAR-J & $\sqrt{ }$ & $\checkmark$ & $\sqrt{ }$ & $\checkmark$ & $\sqrt{ }$ & $\checkmark$ \\
\hline - HAR-CJ & - & - & $\checkmark$ & $\checkmark$ & $\sqrt{ }$ & $\sqrt{ }$ \\
\hline Heterogeneity & - & - & $\checkmark$ & $\sqrt{ }$ & $\sqrt{ }$ & $\checkmark$ \\
\hline \multicolumn{7}{|c|}{ Panel B. Correlations } \\
\hline Non-normality & $\sqrt{ }$ & $\sqrt{ }$ & $\checkmark$ & $\checkmark$ & $\sqrt{ }$ & $\checkmark$ \\
\hline Long-memory & $\sqrt{ }$ & $\checkmark$ & $\checkmark$ & $\sqrt{ }$ & $\sqrt{ }$ & $\checkmark$ \\
\hline Asymmetry & $\sqrt{ }$ & $\checkmark$ & $\checkmark$ & $\sqrt{ }$ & $\sqrt{ }$ & $\checkmark$ \\
\hline - Frequency & $\sqrt{ }$ & $\checkmark$ & $\checkmark$ & $\sqrt{ }$ & $\sqrt{ }$ & $\sqrt{ }$ \\
\hline - HAR-J & - & - & - & $\sqrt{ }$ & $\sqrt{ }$ & - \\
\hline - HAR-CJ & $\sqrt{ }$ & $\checkmark$ & $\checkmark$ & $\checkmark$ & $\checkmark$ & $\checkmark$ \\
\hline Jumps & $\checkmark$ & $\checkmark$ & $\checkmark$ & $\checkmark$ & $\checkmark$ & $\checkmark$ \\
\hline - HAR-J & - & - & - & $\checkmark$ & $\checkmark$ & - \\
\hline - HAR-CJ & $\sqrt{ }$ & $\checkmark$ & $\checkmark$ & $\checkmark$ & $\sqrt{ }$ & $\sqrt{ }$ \\
\hline Heterogeneity & - & - & - & $\checkmark$ & $\checkmark$ & - \\
\hline
\end{tabular}

Notes. Table 6 summarizes the empirical evidence on distributional, long-memory, asymmetries, jumps and heterogeneity properties of the volatilities and correlations of the five Indian stock indices. $\sqrt{ }$ indicates the existence/significance of a property and - indicates the lack of such a property. 